Kyoto University,

Graduate School of Economics

Discussion Paper Series

Uncertainty Shocks and the Relative Price of Investment Goods

Munechika Katayama and Kwang Hwan Kim

Discussion Paper No. E-16-015

Graduate School of Economics

Kyoto University

Yoshida-Hommachi, Sakyo-ku

Kyoto City, 606-8501, Japan

March, 2017 


\title{
Uncertainty Shocks and the Relative Price of Investment Goods*
}

\author{
Munechika Katayama \\ Kyoto University \\ katayama@econ.kyoto-u.ac.jp
}

\author{
Kwang Hwan Kim \\ Yonsei University \\ kimkh01@yonsei.ac.kr
}

March 6, 2017

\begin{abstract}
This study empirically shows that higher uncertainty leads to not only a simultaneous drop in consumption and investment, but also a rise in the relative price of investment goods. This negative relationship between the relative price and quantity of investment suggests that heightened uncertainty depresses investment as an adverse supply shock to the investment sector. We demonstrate that a two-sector sticky price model with realistic asymmetric sectoral price rigidity can successfully account for our empirical findings. In particular, the underlying mechanism behind the negative relationship between the price and quantity of investment is limited intersectoral factor mobility. By contrast, the standard two-sector model featuring perfect factor mobility causes a negative co-movement between consumption and investment, contradicting the business cycle phenomenon.
\end{abstract}

Keywords: Uncertainty shocks; Sticky prices; Factor mobility; Relative price of investment goods.

JEL Classification: E32

${ }^{*}$ We are grateful to Kengo Nutahara, Takayuki Tsuruga, and Kozo Ueda for their constructive comments on earlier draft of this paper. We thank seminar and conference participants at Yonsei University, Seoul National University, GRIPS, the Economic Theory and Policy Workshop, Fall 2015 Midwest Macro Meetings, the 2015 DSGE Conference, 2016 Taipei International Conference on Growth, Trade, and Dynamics, the 91st WEAI Annual Conference, SWET, Kobe University, Henan University, Bank of Korea, and Otaru University of Commerce for their helpful comments and suggestions. A part of this study was financially supported by JSPS Grants-in-Aid for Scientific Research 15K17020 and by the research grant from The Japan Legislatic Society Foundation. . 


\section{Introduction}

The recent Great Recession has sparked the idea that an increase in uncertainty can be an important driver of economic fluctuations. ${ }^{1}$ According to Bloom (2014)'s calculation on the magnitude of the impact of uncertainty, for example, the size of the uncertainty shock experienced during the Great Recession might account for around one-third of the 9\% drop in GDP versus trend during 2008-2009. Recent empirical results by Alexopoulos and Cohen (2009), Bachmann, Elstner, and Sims (2013), Baker, Bloom, and Davis (2016), Bloom (2009), Jurado, Ludvigson, and Ng (2015), and Leduc and Liu (2016), suggest that uncertainty shocks can produce an adverse effect on aggregate economic activity.

How are uncertainty shocks propagated to the economy? In this study, we present a novel channel through which exogenous changes in uncertainty affect the economy. Using a structural vector autoregression (SVAR) framework, we document that unanticipated increases in uncertainty lead to a simultaneous decline in key macroeconomic variables, such as output, consumption, and investment, and yet an increase in the relative price of investment goods. Along with the comovement among the key macroeconomic variables, we pay a particular attention to uncovering the underlying mechanism behind the estimated relationship between the relative price and production of investment goods.

Our focus on the observed negative relationship between the price and quantity of investment is motivated by the fact that it suggests a new mechanism through which higher uncertainty depresses investment other than a conventional real-options effect. Due to the non-convex nature of adjustment costs, the real-options effect emphasizes the value of waiting and staging flexibility when firms make decisions on investment (e.g., Bloom, 2009; Bloom, Floetotto, Jaimovich, Saporta-Eksten, and Terry, 2012). Higher uncertainty raises the value of waiting so that firms postpone purchases of new capital goods until the uncertainty is resolved. This wait-and-see effect of higher uncertainty on investment is more like a demand-side story, in which we would expect a simultaneous drop in price and quantity of investment goods. Hence, our estimated negative relationship between the relative price and production of investment goods seems at odds with the prediction of a real-

\footnotetext{
${ }^{1}$ Following the literature, we use the term "uncertainty" as shorthand for what would more precisely be referred to as "objective uncertainty" or "risk," in which the probabilities are well understood. There might be an alternative source of uncertainty, that is, ambiguity, in which the probabilities are not well understood.
} 
options effect. The negative relationship instead hints some supply-side effect at work to depress investment in response to uncertainty shocks because it can be interpreted as an inward shift of the supply schedule of investment goods along with the investment demand curve. Our attempt to explore another channel for the propagation of uncertainty shocks other than the real option effect is also motivated by the finding of Bachmann and Bayer (2013), who show that risk shocks exert small aggregate effects through the wait-and-see effect in a heterogeneous-firm DSGE model.

We seek to account for our empirical findings in the context of a two-sector, representative-agent sticky price model that consists of a sticky-price consumption sector and a flexible-price investment sector. There are good reasons to believe that the pricing of the investment sector producing durable goods can be better characterized as flexible rather than as sticky. As Barsky, House, and Kimball (2007) convincingly point out, we tend to bargain over big-ticket, long-lived items. Large durable goods often require considerable customization; this necessitates negotiations, and the discussions about the exact nature of the good are likely to be accompanied by negotiations about prices. This suggests that the transaction prices of many long-lived goods are effectively flexible. In addition to these conceptual reasons, several empirical findings support modeling the investment sector as flexibly priced. ${ }^{2}$

We show that the introduction of imperfect intersectoral factor mobility is the key to constructing a satisfactory two-sector sticky price model that generates our empirical findings. An important channel through which higher uncertainty causes relative price of investment to rise is that because of the limited factor mobility, factor prices are not immediately equalized across sectors in response to uncertainty shocks. As a result, the imperfect factor mobility generates a rise in the intersectoral factor prices differential following uncertainty shocks, so that the relative price of investment fluctuates. In particular, we demonstrate that the imperfect factor mobility temporarily makes the period after heightened uncertainty a more expensive time to produce investment than consumption goods, which thus makes uncertainty shocks behave like adverse supply shocks to the investment sector. As a result, the relative price of investment temporarily increases with higher uncertainty. An increase in the intertemporal relative price of investment goods induces a shift of expenditure

\footnotetext{
${ }^{2}$ Bils, Klenow, and Malin (2013) find that residential housing and structure are flexibly priced based on estimating the frequency of price adjustment using micro data. Furthermore, Bouakez, Cardia, and Ruge-Murcia (2009) and Kim and Katayama (2013) find that the construction and durable goods sectors have flexible prices based on macroeconometric estimates of multi-sector DSGE models.
} 
away from those goods, which in turn causes the production of investment goods to fall. Therefore, the introduction of imperfect factor mobility opens the door for sticky price models to account for the observed responses of the relative price and production of investment.

The natural question is then why factor prices in investment sector become more expensive than those in consumption sector in the model with imperfect factor mobility. This stems from the precautionary saving effect. Higher uncertainty induces the household to save more and thus decrease the demand for current consumption. Since production is demand-determined if prices are sticky, production of sticky-price consumption goods falls in response to uncertainty shocks. As production of consumption sector contracts, factor prices in consumption sector become cheaper than those in investment sector on impact after uncertainty shocks. This intersectoral factor prices differential does not immediately disappear due to the imperfect factor mobility, which contributes to a temporary increase in the relative price of investment goods. Even though investment sector pays higher wages and rental rates than consumption sector, workers and capital cannot reallocate from the consumption to investment sector, so that factor prices in the consumption sector remain low relative to those in the investment sector. In contrast, if factors were perfectly mobile, workers and capital would immediately flow from consumption toward investment sector to exploit higher factor prices. As a result, wages and rental rates in each sector would be equalized right away following uncertainty shocks. Below we present empirical evidence consistent with imperfect intersectoral factor mobility by estimating the response of the ratio of investment-sector to consumption-sector wages to uncertainty shocks.

While the imperfect factor mobility works to raise the relative price of investment, there is also counteracting force against it. As previous studies emphasize (e.g., Basu and Bundick, 2012; Fernández-Villaverde, Guerrón-Quintana, Kuester, and Rubio-Ramírez, 2015), in the representativeagent models, higher uncertainty induces the households precautionary labor supply effect. Since heightened uncertainty raises the value of marginal utility of wealth due to the precautionary saving effect, households find it optimal to supply more labor for a given level of real wages. This, in turn, reduces firms marginal costs in each sector. The precautionary labor supply effect has a different impact on the price markups in each sector, which causes the relative price of investment to fall. To be more specific, the price markups on consumption goods with sticky prices rise above their desired levels. In contrast, for producers in the flexible-price investment sector, the period after 
heightened certainty is a less expensive time to produce because of the precautionary labor supply effect. They simply charge a lower price to maintain their markup. Due to this differential impact of the precautionary labor supply on the sectoral price markups, the precautionary labor supply effect lowers the relative price of investment goods following uncertainty shocks.

Hence, if the imperfect factor mobility effect is strong enough to dominate the precautionary labor supply effect, the relative price of investment goods can indeed temporally increase following uncertainty shocks. As a consequence, production of investment goods falls. Given that production of consumption goods also falls, this implies that the model with imperfect factor mobility can produce a rise in the relative price of investment as well as a simultaneous decline in consumption and investment.

All the discussion above explains why the standard two-sector sticky price model in which factors freely move across sectors fails to generate the observed responses of the relative price and production of investment goods to uncertainty shocks. Only the precautionary labor supply effect is operative in the standard model, so that uncertainty shock is thus merely a beneficial supply shock to the flexible-price investment sector in that model. As a result, the relative price of investment goods becomes temporally cheaper following the increase in uncertainty. A decline in the intertemporal relative price of investment goods triggers a large shift of expenditure toward the investment sector and thereby causes a pronounced expansion in production of investment goods. Surprisingly, the increase in production of investment sector can be so large that GDP and aggregate hours rise in response to uncertainty shocks.

This unexpected result is even more striking when it contrasts with that of a one-sector sticky price model, isomorphic to the standard two-sector sticky price model with symmetric price rigidity across sectors. As shown by Basu and Bundick (2012), higher uncertainty generates an adverse effect on GDP and aggregate hours in the one-sector model. It is then natural to think that the introduction of a flexible-price investment sector would not have a drastic impact on the equilibrium path of GDP and aggregate hours since production of consumption goods, which accounts for the lions share of GDP, is characterized by sticky prices. Contrary to this logic, the presence of flexible-price investment goods can undo the implications of a one-sector sticky price model. Interestingly, this surprising behavior resembles that of Barsky, House, and Kimball (2007). As they demonstrate that the presence of flexibly priced durable goods alters the impact of monetary shocks, we show that 
the presence also fundamentally changes the way uncertainty shocks affect the economy compared to a one-sector sticky price model.

Finally, empirical evidence supporting the notion that labor and capital cannot be immediately reallocated between sectors has been well established. Imperfect intersectoral labor mobility is consistent with persistent sectoral wage differentials (e.g., Krueger and Summers, 1988; Neumuller, 2015). Horvath (2000) and Katayama and Kim (2015) report low estimates of intersectoral labor substitutability. Beaudry and Portier (2011) present empirical evidence that intersectoral labor mobility is not sufficient, so that the returns to labor between individuals initially attached to different sectors is not equated. Davis and Haltiwanger (2001) find that reallocation friction is an important channel through which oil shocks drive economic fluctuations. Ramey and Shapiro (2001) document high costs associated with reallocating capital across sectors.

The rest of this paper is organized as follows. Section 2 presents our empirical findings showing that a positive innovation to the empirical uncertainty measure leads to a simultaneous drop in macroeconomic variables and to an increase in the relative price of investment goods. Section 3 presents our two-sector sticky price model. In Section 4, we show, both analytically and numerically, that our two-sector sticky price model featuring imperfect factor mobility can account for our empirical findings. Section 5 explains why the standard model with perfect factor mobility fails to match our empirical evidence. Finally, Section 6 concludes.

\section{Empirical Findings}

We start our analysis by documenting the impact of uncertainty shocks on key macroeconomic variables using a standard SVAR model. We focus on the joint effects of uncertainty shocks on consumption, investment, and the relative price of investment. The dynamic interaction between uncertainty and the relative price is of particular interest to us.

How the relative price responds to uncertainty shocks provides useful information that helps us understand the nature of their propagation mechanism. If higher uncertainty causes investment to drop in the data, is this due to the wait-and-see effect, which makes firms postpone purchase of capital? In principle, if this effect were strong, we should not observe an increase in the relative price of investment goods following higher uncertainty. If the relative price instead rises, this suggests 


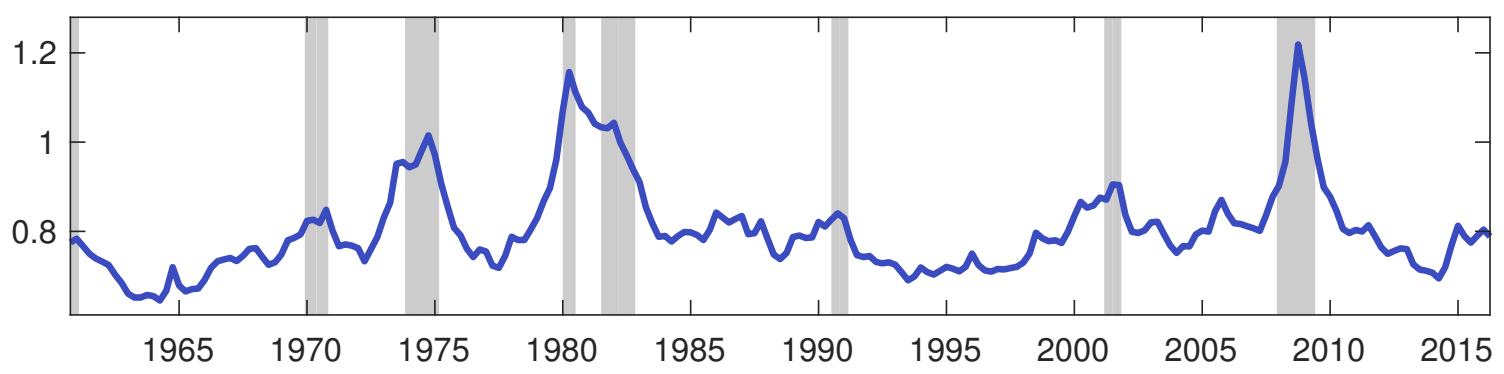

(a) Aggregate Uncertainty Measure

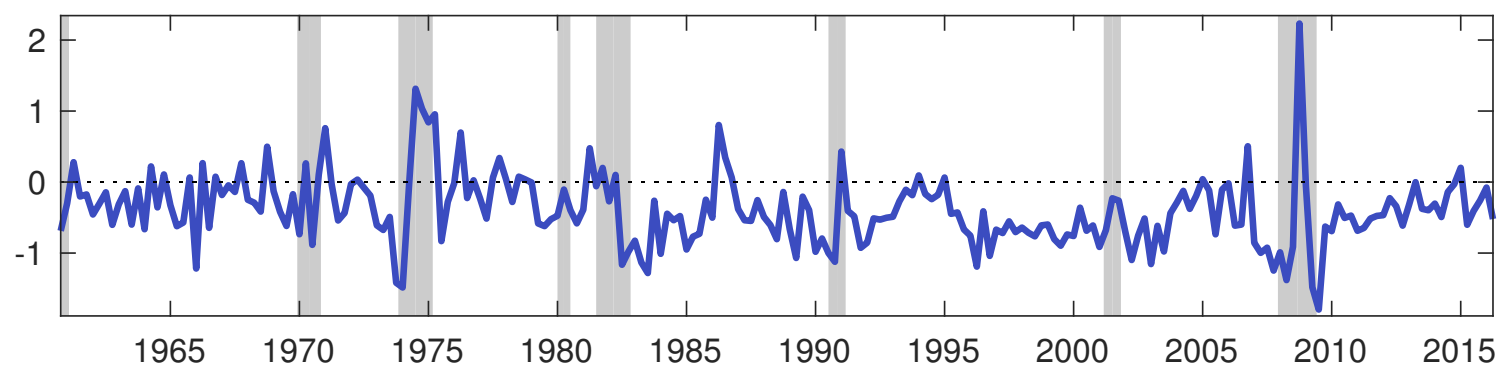

(b) Percentage Changes in the Relative Price of Investment Goods

Figure 1: Uncertainty Measure and the Relative Price of Investment Goods

Note: The upper panel presents the aggregate uncertainty measure from Jurado, Ludvigson, and Ng (2015), updated by Ludvigson et al. (2016). We use the quarterly average of their monthly series with $h=3$ (i.e., 3-month-ahead uncertainty). The bottom panel shows percentage changes in the relative price of investment goods.

that there are other forces that depress investment from the supply side of the investment sector.

Our SVAR specification allows us to address this issue. Existing empirical studies, however, focus more on whether uncertainty shocks have an adverse impact on real activity. ${ }^{3}$ Most previous studies examine whether uncertainty shocks affect unemployment, industrial production or inflation per se, but not how the uncertainty shocks are propagated to the economy. ${ }^{4}$ If the uncertainty shocks depress economic activity, we seek here to inspect the mechanism through which they do so.

\subsection{Data}

As a starting point, Figure 1 plots the measure of uncertainty and the percentage changes in the relative price of investment goods, which we define later in this section. Interestingly, all major spikes

\footnotetext{
${ }^{3}$ Examples include Alexopoulos and Cohen (2009), Bachmann, Elstner, and Sims (2013), Baker, Bloom, and Davis (2016), Bloom (2009), Born, Breuer, and Elstner (2014), Caggiano, Castelnuovo, and Groshenny (2014), Carriero, Mumtaz, Theodoridis, and Theophilopoulou (2015), Jurado, Ludvigson, and Ng (2015), and Leduc and Liu (2016).

${ }^{4}$ An important exception is Gilchrist, Sim, and Zakrajšekek (2014). Using SVAR, they examine the aggregate implications of the dynamic interaction between uncertainty and financial conditions to show the mechanism through which the uncertainty shock affect the economy. They demonstrate that the impact of uncertainty on investment occurs primarily through changes in credit spreads.
} 
in uncertainty are associated with increases in the relative price of investment goods. Furthermore, those spikes are related to severe recessions, such as 1973-1975, 1981-1982, and 2007-2009 recessions. This observation suggests that an increase in uncertainty might operate as an adverse supply shock to the investment sector, resulting in a rise in the relative price and a decline in the production of investment goods. This, in turn, might contribute to economic downturns. To confirm this visual impression, we formally examine the dynamic relationship between the empirical measure of uncertainty and the relative price of investment goods using a standard recursively identified VAR.

Our baseline specification of SVAR system consists of 9 variables in the following order: aggregate macro uncertainty measure, per capita real GDP, per capita real consumption, GDP deflator, per capital real investment, per capita hours worked, real wage, the federal funds rate, and the relative price of investment goods. ${ }^{5}$ These variables are similar to those considered in Justiniano, Primiceri, and Tambalotti (2011). All variables are logged, except for the uncertainty measure, and federal funds rate. We include four lags in the estimation.

As a measure of uncertainty, we use the macro uncertainty estimate of Jurado, Ludvigson, and $\mathrm{Ng}$ (2015) updated by Ludvigson, Ma, and $\mathrm{Ng}(2016) .{ }^{6}$ One advantage of doing so is that its sample period, starting from 1960:Q3, is the longest among other popular uncertainty measures. Another motivation for using this measure is that it captures the common variation in the unforecastable component of a large number of economic indicators. Jurado, Ludvigson, and $\mathrm{Ng}$ (2015) show that much of the variation of popular uncertainty proxies is not generated by movement in genuine uncertainty across the broader economy. ${ }^{7}$ In addition, they demonstrate that popular uncertainty

\footnotetext{
${ }^{5}$ We retrieve the following variables from the FRED of St. Louis Fed (FRED series IDs are in parentheses): Civilian Noninstitutional Population (CNP16OV), Nonfarm Business Sector: Compensation Per Hour (COMPNFB), Personal consumption expenditures: Durable goods (chain-type price index, DDURRG3Q086SBEA, Personal consumption expenditures: Nondurable goods (chain-type price index, DNDGRG3Q086SBEA), Personal consumption expenditures: Services (chain-type price index, DSERRG3Q086SBEA), Effective Federal Funds Rate (FEDFUNDS), Gross Domestic Product (GDP), Gross Domestic Product: Implicit Price Deflator (GDPDEF), Gross Private Domestic Investment (GPDI), Gross Private Domestic Investment: Chain-type Price Index (GPDICTPI), Nonfarm Business Sector: Hours of All Persons (HOANBS), Personal Consumption Expenditures: Durable Goods (PCDG), Personal Consumption Expenditures: Services (PCESV), Personal Consumption Expenditures: Nondurable Goods (PCND). We construct price indices for consumption and investment by using the Törnqvist index. Then, we obtain the quantity indices by deflating the expenditures. Per capita variables are divided by the HP trend of the population data since it has a couple of jumps.

${ }^{6}$ While Ludvigson, $\mathrm{Ma}$, and $\mathrm{Ng}$ (2016) compute both macro and financial uncertainty measures, we use the macro uncertainty measure. The updated version of the aggregate uncertainty series, covering up to 2016:06, is obtained from the author's web site, http://www.sydneyludvigson.com/s/MacroFinanceUncertainty_2016Aug_update.zip.

${ }^{7}$ One popular practice in the literature is to use an observable proxy for uncertainty. For example, Bloom (2009) uses the VIX index, the implied stock market volatility based on the S\&P 500 index, and Bloom, Floetotto, Jaimovich, SaportaEksten, and Terry (2012) use the cross-sectional dispersion of productivity. Another popular proxy for uncertainty is the cross-sectional dispersion of individual forecasts, as in Bachmann, Elstner, and Sims (2013).
} 
proxies erroneously attribute forecastable fluctuations to a movement in uncertainty. Jurado, Ludvigson, and $\mathrm{Ng}$ (2015) address these problems and construct new estimates of aggregate uncertainty. Although they provide three monthly measures (1-month-, 3-month-, 12-month-ahead uncertainty measures), we use the 3-month-ahead uncertainty measure for consistency with our setup. We convert it to a quarterly series by taking the quarterly average.

Following Justiniano, Primiceri, and Tambalotti (2011), we construct the relative price of investment goods as the ratio of the chain-weighted deflator for investment to that of consumption. For the denominator, we use National Income and Product Accounts (NIPA) deflators for personal consumption expenditures on nondurables and services and for the numerator we use NIPA deflators for durable consumption and gross private investment. Consumption covers nondurable goods and services and investment consists of durable goods consumption and gross private investment. All real variables are then deflated by the price of consumption.

Our sample starts from 1960:Q3 and ends in 2016:Q2. Since the sample includes a period during which the federal funds rate hits the zero lower bound (ZLB), we use the shadow federal funds rate constructed by $\mathrm{Wu}$ and Xia (2016), which is not bounded below by zero and is supposed to summarize the stance of monetary policy. ${ }^{8}$ From 2009:Q1 to 2015:Q4, we replace the effective federal funds rate by the $\mathrm{Wu}-\mathrm{Xia}$ shadow rate.

\subsection{Results}

To identify uncertainty shocks, we employ a standard Cholesky decomposition. The ordering of the variables is the same as we described earlier in this section. Ludvigson, $\mathrm{Ma}$, and $\mathrm{Ng}$ (2016) cast some doubt about the validity of the commonly used recursive identification scheme. Using a less restrictive SVAR system, which allows for contemporaneous feedback between uncertainty and real activity, they argue that predictions from recursive identification could be misleading. One potential drawback of their identification strategy is that it is only applicable to a small SVAR system. Although it is less restrictive in terms of the timing assumption, additional restrictions are necessary to achieve identification. While it is quite important to investigate whether uncertainty is a cause or a consequence of changes in the economic activity, we also believe that it is equally

\footnotetext{
${ }^{8}$ We obtain the shadow federal funds rate series from https://www.frbatlanta.org/cqer/research/shadow_rate.aspx, which is maintained and updated by the Atlanta Fed.
} 

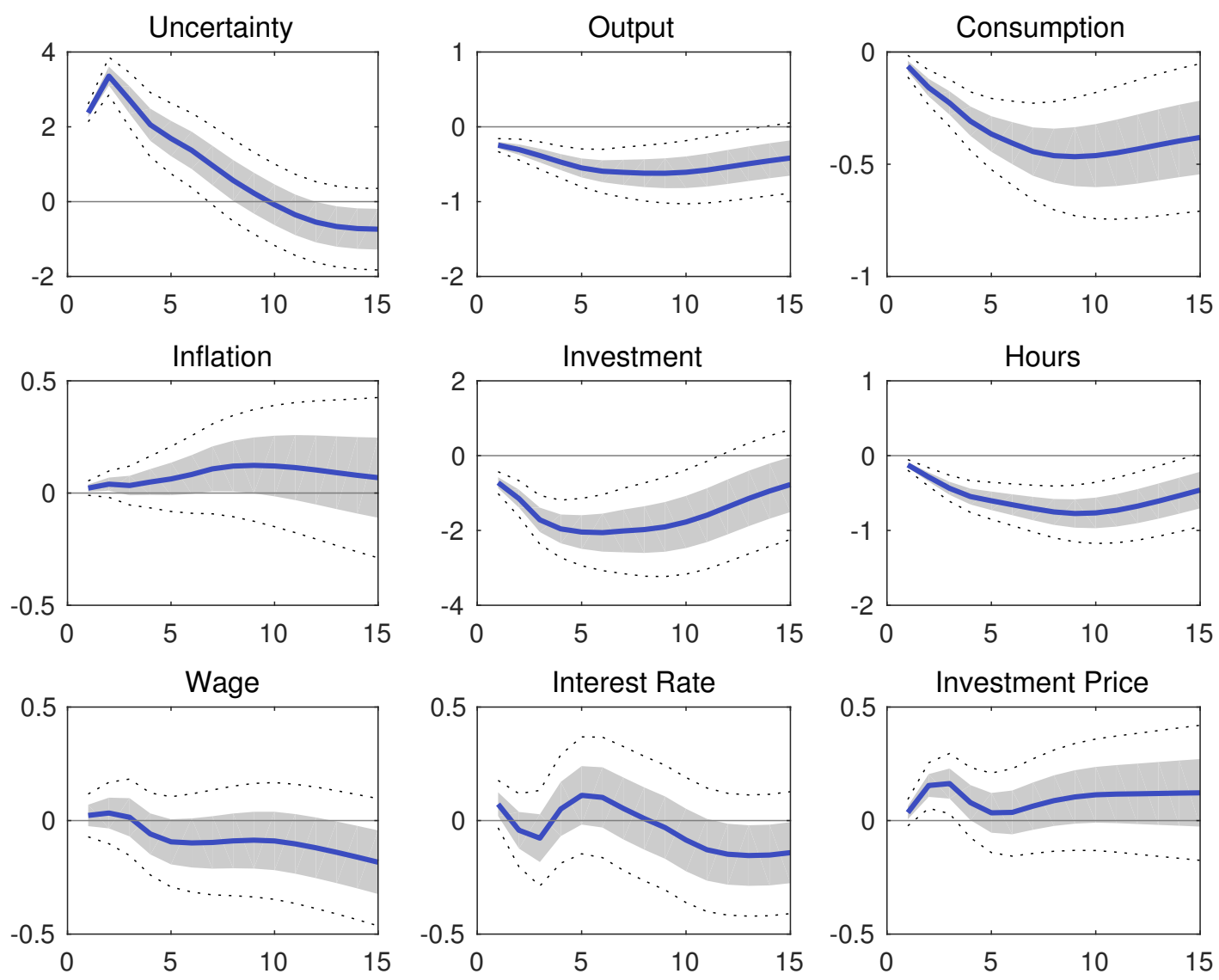

Figure 2: Empirical Responses to the Uncertainty Shock from VAR

Note: The horizontal axes measure quarters. The vertical axes are percentage deviations from the unshocked path. The shaded areas and dashed lines represent one- and two-standard-error confidence bands, respectively. They are based on 1,000 bootstrap repetitions.

important to document how a set of macroeconomic variables dynamically responds with a larger recursive system. Later, we will examine the robustness of our results to the possibility that changes in uncertainty are endogenous.

Figure 2 presents the responses of macroeconomic variables to a one-standard-deviation innovation to the uncertainty measure. In response to the uncertainty shock, the relative price of investment goods increases significantly in the second and third quarters. Furthermore, the uncertainty shock results in a simultaneous drop in consumption, investment, and output, which is a standard business cycle feature. They decrease together significantly for more than 10 quarters. Even though Leduc and Liu (2016) find that higher uncertainty reduces inflation significantly at a monthly frequency in a smaller SVAR system, we find no such evidence. 


\subsection{Robustness Checks}

These results are robust to different specifications. ${ }^{9}$ Figure 3 summarizes responses of the selected variables to the uncertainty shocks under different specifications. The ordering of variables does not affect the VAR results shown in Figure 2. In particular, even when we treat the macro uncertainty measure as endogenous (placed last in the Cholesky ordering), the qualitative results remain unchanged as shown in the first row of Figure 3 labeled "Last". In addition, the second row of Figure 3 labeled "Quality Adj." presents that using a quality-adjusted investment deflator has no discernible effect on the VAR results. ${ }^{10}$ Furthermore, similar results emerge even when we use the VIX index, which is also a widely used proxy for uncertainty, instead of the uncertainty measure of Jurado, Ludvigson, and $\mathrm{Ng}$ (2015). As shown in the third row of Figure 3, the relative price of investment goods increases and investment drops significantly for the first couple of periods when uncertainty becomes higher. Hence, the negative correlation between the price and production of investment is preserved even with the VIX index as a measure of uncertainty shocks. However, the decline in consumption and output becomes statistically insignificant, so that the co-movement among output, consumption, and investment is less evident when the VIX index is used.

Besides uncertainty shocks, there are other types of shocks that might cause the relative price of investment to increase. If the investment sector has flexible prices, which we will assume in the subsequent sections below, any exogenous increases in costs of production can be translated to an increase in the relative price of investment goods. One candidate might be oil shocks. Moreover, because almost all post-World-War-II recessions, in which uncertainty rise as shown in Figure 1, are also typically preceded by spikes in oil prices (e.g. Hamilton, 1983), it is possible that uncertainty shocks in our VAR specification are compounded by oil shocks. This implies that our estimated response of the relative price of investment to an increase in uncertainty might be spurious. To address this issue, we augment the VAR specification by including a measure of oil price shocks. Following Hamilton $(1996,2003)$, we construct the 3-year Net Oil Price Increase (NOPI) as a measure of oil price shocks, using the West Texas Intermediate price. We place it first in the Cholesky ordering.

The fourth row of Figure 3 labeled "NOPI" displays the estimated responses of the selected

\footnotetext{
${ }^{9}$ Qualitatively speaking, excluding the ZLB periods from our sample has no discernible effect on the VAR results.

${ }^{10}$ The quality-adjusted investment deflator (INDEV) is based on DiCecio (2009) and is updated at FRED of the St. Louis Fed.
} 

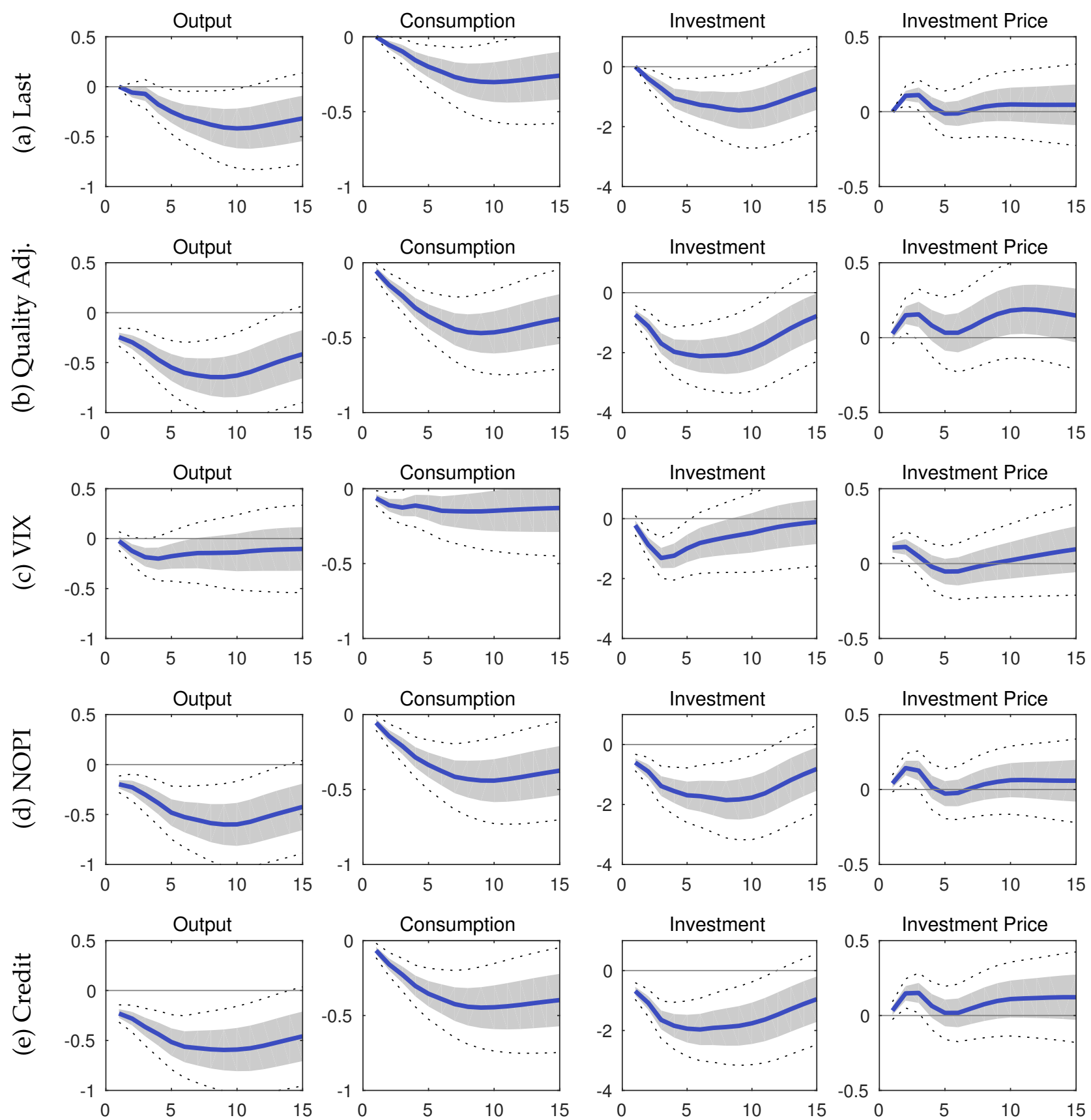

Figure 3: Robustness Check: Estimated Responses of Selected Variables to the Uncertainty Shocks

Note: The first row labeled "Last" shows responses when the uncertainty measure is placed last in the Cholesky ordering. The second row labeled "Quality" corresponds to the case with the quality-adjusted relative price series. The third row labeled "VIX" displays responses of the variables when we use the VIX index as a measure of uncertainty. The fourth row labeled "NOPI" and fifth row labeled "Credit" show those with NOPI and the credit spread, respectively. The horizontal axes measure quarters. The vertical axes are percentage deviations from the unshocked path. The shaded areas and dashed lines represent one- and two-standard-error confidence bands, respectively. They are based on 1,000 bootstrap repetitions. 

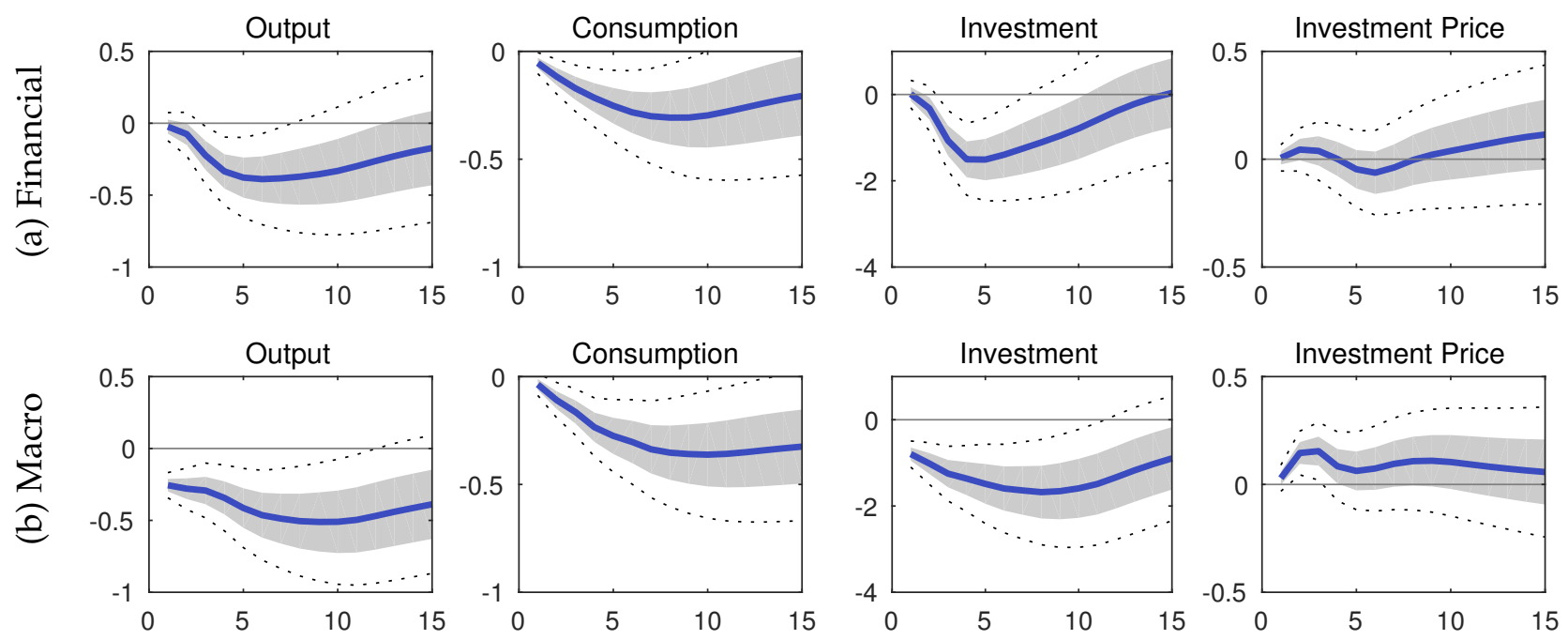

Figure 4: Estimated Responses to the Uncertainty Shocks in the Hybrid Specification

Note: The first row labeled "Finanial" shows responses to the financial uncertainty shock when we include both the financial and macro uncertainty measures. The second row labeled "Macro" displays those to the macro uncertainty shock in the hybrid specification. The horizontal axes measure quarters. The vertical axes are percentage deviations from the unshocked path. The shaded areas and dashed lines represent one- and two-standard-error confidence bands, respectively. They are based on 1,000 bootstrap repetitions.

variables to a one standard deviation shock to the uncertainty measure. The qualitative results remain unchanged even with the inclusion of the NOPI. Despite the potential concern that the relative price response could be contaminated by cost shocks, the relative price exhibits more pronounced responses to the uncertainty shock.

As Gilchrist, Sim, and Zakrajšekek (2014) demonstrate, uncertainty shocks can also affect investment through their impact on credit spreads. To address such a possibility, we augment the VAR system by including the difference between Baa corporate bond yield and 10-year Treasury (BAA10YM) as a measure of credit spread, placed before the Federal funds rate. The fifth row of Figure 3 demonstrates that quantitative results remain unchanged after controlling for interactions between investment and the credit spread.

Ludvigson, $\mathrm{Ma}$, and $\mathrm{Ng}$ (2016) make a distinction between the measures for macro uncertainty and financial uncertainty. While we use the former as a measure of uncertainty, the latter is constructed from squared forecast errors of monthly financial variables covering the bond market, stock market portfolio returns, and commodity markets. Ludvigson, $\mathrm{Ma}$, and $\mathrm{Ng}$ (2016) argue that shocks to the financial uncertainty can increase the observed measure of macro uncertainty. This raises a concern that an increase in the relative price investment might be due to financial uncertainty 
shocks, not macro uncertainty shocks. To address this concern, we include both the financial and macro uncertainty measures at once, placed the financial uncertainty measure first preceded to the macro uncertainty measure. Figure 4 presents impulse responses from this hybrid specification.

The first row of Figure 4 labeled "Financial" shows responses of the selected variables to the financial uncertainty shock. Interestingly, we do not find any significant responses of the relative price of investment. In contrast, the second row of Figure 4 labeled "Macro," clearly shows that the relative price of investment continue to increase in response to the macro uncertainty shock, even when the system is augmented by the financial uncertainty measure. In terms of the comovement, on the other hand, both the financial and macro uncertainty shocks shares the same feature. GDP, consumption, and investment drop together, which is a typical characteristic of business cycles. Hence, the increase in the relative price of investment goods is a distinct feature of macro uncertainty shocks. This result lends support to our choice of modeling uncertainty shocks as stochastic volatility in the aggregate technology in the subsequent sections.

In the following sections, we focus on two empirical findings: (i) the rise in the relative price of investment goods (negative correlation between the quantity and price of investment goods), and (ii) co-movement among the key macroeconomic variables, such as output, consumption, and investment.

\section{Model}

In this section, we present the two-sector sticky price model that generate our empirical findings. The key to the model is to introduce imperfect intersectoral factor mobility, supported by previous studies. For example, Ramey and Shapiro (2001) document the high costs associated with reallocating capital across sectors. Beaudry and Portier (2011) present empirical evidence that intersectoral labor mobility is not perfect, so that the returns to labor between individuals initially attached to different sectors is not equated. Krueger and Summers (1988) and more recently Neumuller (2015) have documented persistent intersectoral wage differentials, consistent with the notion of imperfect intersectoral labor mobility. Given the empirical support, we consider it reasonable to allow for some degree of intersectoral factor immobility in the model.

The economy is populated by an infinitely-lived representative household, continua of firms in 
the two sectors that produce differentiated consumption and investment goods, perfectly competitive final goods firms in the two sectors, and a monetary authority.

\subsection{Households}

The representative household receives utility from consumption and incurs disutility from allocating labor hours to the consumption and investment goods sectors. Let $C_{t}$ and $N_{t}$ denote period $t$ consumption and an aggregate labor index, respectively. The household maximizes expected discounted lifetime utility, given by

$$
U_{0}=E_{0}\left[\sum_{t=0}^{\infty} \beta^{t} U\left(C_{t}, N_{t}\right)\right]
$$

where $\beta \in(0,1)$ is the subjective discount factor.

We use the conventional King-Plosser-Rebelo momentary utility function adopted by Basu and Kimball (2002), Shimer (2009), and Katayama and Kim (2015):

$$
U\left(C_{t}, N_{t}\right)=\frac{C_{t}^{1-\frac{1}{\gamma}}\left(1+\left(\frac{1}{\gamma}-1\right) v\left(N_{t}\right)\right)^{\frac{1}{\gamma}}-1}{1-\frac{1}{\gamma}}
$$

where $v\left(N_{t}\right)=v \frac{\eta}{1+\eta} N_{t} \frac{\eta+1}{\eta}$ and $\gamma$ controls the intertemporal elasticity of substitution as well as the degree of non-separability between consumption and leisure. $v\left(N_{t}\right)$ measures the disutility incurred from hours worked with $v^{\prime}>0, v^{\prime \prime}>0$ and $\eta$ is the Frisch elasticity of aggregate labor supply when preference is separable. Labor can flow freely across sectors. Hence, $N_{t}=N_{c, t}+N_{i, t}$, where $N_{c, t}$ and $N_{i, t}$ represent labor hours devoted to consumption and investment sectors, respectively.

The household enters a period $t$ with a stock of private one-period nominal bonds $B_{t-1}$. During this period, the household receives wages, rental rates, dividends paid by firms, and interest payments on bond holdings. These resources are used to purchase consumption and investment goods, and to acquire assets to be carried over to the next period. Then, the household's budget constraint is

$$
C_{t}+\left(\frac{P_{i, t}}{P_{c, t}}\right) I_{t}+\frac{B_{t}}{P_{c, t}} \leq R_{t-1} \frac{B_{t-1}}{P_{c, t}}+\sum_{j=c, i}\left(\frac{W_{j, t}}{P_{c, t}}\right) N_{j, t}+\sum_{j=c, i}\left(\frac{R_{j, t}^{k}}{P_{c, t}}\right) K_{j, t}+\sum_{j=c, i} D_{j, t},
$$

where the subscripts $c$ and $i$ denote variables specific to the consumption and investment sector, 
respectively, $P_{j, t}$ is the nominal price in sector $j=c, i, I_{t}=I_{c, t}+I_{i, t}$, where $I_{j, t}$ represents newly purchased capital in sector $j$, and $W_{j, t}$ is the nominal wage rate paid by firms in sector $j$. In addition, $K_{j, t}$ is productive capital stock in sector $j$ and $R_{j, t}^{k}$ is the rental rate of capital services in sector $j . R_{t}$ is the gross nominal interest rate and $D_{j, t}$ is the real dividend from profit.

We model inflexible intersectoral labor mobility by assuming that labor devoted to each sector is imperfect substitutes to the representative household, which inhibits labor from moving across sectors. This assumption is motivated by the findings of Horvath (2000), and Katayama and Kim (2015), who report a relatively low estimate for the elasticity of substitution of labor across sectors. In order to capture some degree of sector specificity to labor parsimoniously, while not deviating from the representative household assumption, we use the following aggregate labor index:

$$
N_{t}=\left[N_{c, t}^{\frac{\theta+1}{\theta}}+N_{i, t}^{\frac{\theta+1}{\theta}}\right]^{\frac{\theta}{\theta+1}}
$$

where $\theta \geq 0$ captures the degree of imperfect intersectoral mobility of labor. To understand the implications of specification (4) better, it is useful to note that the marginal rate of transformation $(M R T)$ between consumption-sector labor $\left(N_{c, t}\right)$ and investment-sector labor $\left(N_{i, t}\right)$ is given by

$$
M R T \equiv\left(\frac{N_{c, t}}{N_{i, t}}\right)^{\frac{1}{\theta}}=\frac{W_{c, t}}{W_{i, t}}
$$

where $W_{j, t}$ is the nominal wage in sector $j$. If $\theta \rightarrow \infty$, then the elasticity of substitution between $N_{c, t}$ and $N_{i, t}$ becomes infinity and MRT is unity, which is a feature of the standard two-sector model. Specifically, by reducing the labor used for producing consumption goods by one unit, it is possible to increase the labor that can be used for producing investment goods by one unit without any need to increase aggregate labor. This implies that it is very easy to reallocate labor from one sector to another, so that each sector pays the same wages. When $\theta<\infty$, the MRT becomes smaller as the household increases the composition of labor more toward the investment sector (i.e., a larger value of $\left.N_{i, t} / N_{c, t}\right)$. This might capture an aspect of the labor market in which workers cannot be retrained immediately to produce computers and structures instead of food and entertainment services. In this case, the household might be reluctant to switch from consumption-sector labor toward investment-sector labor, even though the latter pays higher wages than the former. 
In addition, we assume that capital is immobile across sectors by specifying separate accumulation equations for the capital stocks in each sector. In other words, the capital stock in each sector evolves according to

$$
K_{j, t+1}=I_{j, t}\left[1-\frac{\kappa_{j}}{2}\left(\frac{I_{j, t}}{I_{j, t-1}}-1\right)^{2}\right]+(1-\delta) K_{j, t}, \quad j=c, i .
$$

Here, $\delta$ is a depreciation rate and $\kappa$ controls the size of adjustment costs when the level of investment changes over time, proposed by Christiano, Eichenbaum, and Evans (2005). (6) captures the notion that capital used in the production of heavy industrial equipment cannot be used to produce food or entertainment.

\subsection{Firms}

We assume the existence of a continuum of monopolistically competitive firms, indexed by $s \in[0,1]$, which produce differentiated intermediate goods in each sector. A final good in each sector is produced by a perfectly competitive representative firm. The firm produces the final good by combining a continuum of intermediate goods.

Final goods firms. The final good in each sector, $Y_{j, t}$, is aggregated by the constant elasticity of substitution technology:

$$
Y_{j, t}=\left(\int_{0}^{1} Y_{j, t}(s)^{\frac{\varepsilon_{j}-1}{\varepsilon_{j}}} d s\right)^{\frac{\varepsilon_{j}}{\varepsilon_{j}-1}} .
$$

Here, $Y_{j, t}(s)$ is the differentiated intermediate inputs produced by firm $s$ in sector $j$, and the parameter $\varepsilon_{j}$ represents the elasticity of substitution of intermediate goods in sector $j$.

A cost minimization problem for the final good producer in each sector implies that the demand for intermediate goods is given by

$$
Y_{j, t}(s)=\left(\frac{P_{j, t}(s)}{P_{j, t}}\right)^{-\varepsilon_{j}} Y_{j, t}
$$

where $P_{j, t}(s)$ is the price of intermediate good $s$ in sector $j=c, i$ and $P_{j, t}$ is the sectoral price level in 
sector $j=c, i$. Finally, the zero-profit condition implies that the sectoral price index is expressed as

$$
P_{j, t}=\left(\int_{0}^{1} P_{j, t}(s)^{1-\varepsilon_{j}} d s\right)^{\frac{1}{1-\varepsilon_{j}}} .
$$

Intermediate goods firms. Intermediate goods producers in each sector are monopolistically competitive. Each intermediate goods firm uses capital $K_{j, t}(s)$ and labor $N_{j, t}(s)$ to produce its differentiated products $Y_{j, t}(s)$ using the following production function:

$$
Y_{j, t}(s)=A_{t} K_{j, t}(s)^{\alpha} N_{j, t}(s)^{1-\alpha}-F_{j}
$$

where $\alpha \in(0,1), F_{j}$ denotes the fixed cost of production, and $A_{t}$ is the level of aggregate total factor productivity.

The intermediate goods firms in each sector are subject to nominal rigidities. Given the demand function, the monopolistically competitive intermediate goods firms maximize profits by setting prices subject to adjustment costs, as in Rotemberg (1982). Thus, firm $s$ in sector $j$ solves:

$$
\begin{gathered}
\max \quad E_{t} \sum_{v=0}^{\infty} \beta^{v} \frac{\lambda_{t+v}}{\lambda_{t}}\left\{\frac{P_{j, t+v}(s)}{P_{j, t+v}} Y_{j, t+v}(s)-\frac{M C_{j, t+v}}{P_{j, t+v}} Y_{j, t+v}(s)-\frac{\phi_{p_{j}}}{2}\left(\frac{P_{j, t+v}(s)}{\pi_{j} P_{j, t+v-1}(s)}-1\right)^{2} Y_{j, t+v}\right\} \\
\text { s.t. } Y_{j, t}(s)=\left(\frac{P_{j, t}(s)}{P_{j, t}}\right)^{-\varepsilon_{j}} Y_{j, t},
\end{gathered}
$$

where $\lambda_{t}$ is the Lagrange multiplier on the household's budget constraint (3), $M C_{j, t}$ is a nominal marginal cost in sector $j$, and $\phi_{p_{j}}$ is a parameter measuring the degree of price rigidity in sector $j$.

\subsection{Equilibrium}

The Rotemberg-style pricing allows us to assume a symmetric equilibrium, in which each firm makes the same decision so that $N_{j, t}(s)=N_{j, t}, K_{j, t}(s)=K_{j, t}, Y_{j, t}(s)=Y_{j, t}$, and $P_{j, t}(s)=P_{j, t}$, for all $s$. In the equilibrium, net private debt $B_{t}=0$ and goods market clearing requires the following:

$$
\begin{aligned}
& Y_{c, t}=C_{t}+\frac{\phi_{p_{c}}}{2}\left(\frac{\pi_{c, t}}{\pi_{c}}-1\right)^{2} Y_{c, t}, \\
& Y_{i, t}=I_{t}+\frac{\phi p_{i}}{2}\left(\frac{\pi_{i, t}}{\pi_{i}}-1\right)^{2} Y_{i, t} .
\end{aligned}
$$




\subsection{Monetary authority}

The monetary authority conducts monetary policy using the short-term nominal interest rate as the policy instrument. The gross nominal interest rate $R_{t}$ follows a Taylor rule of the following type

$$
\frac{R_{t}}{R}=\left(\frac{R_{t-1}}{R}\right)^{\rho_{R}}\left(\frac{\Pi_{t}}{\Pi}\right)^{\rho_{\pi}\left(1-\rho_{R}\right)}\left(\frac{Y_{t}}{Y_{t-1}}\right)^{\rho_{Y}\left(1-\rho_{R}\right)}
$$

where $\Pi_{t}$ is an economy-wide inflation rate, $Y_{t}$ is real GDP, and $R$ and $\Pi$ are the steady-state gross nominal interest rate and inflation rate, respectively. The economy-wide total output (real GDP) $Y_{t}$ is given by

$$
Y_{t}=Y_{c, t}+\frac{P_{i}}{P_{c}} Y_{i, t}
$$

where $P_{i} / P_{c}$ is the steady-state relative price of investment goods. We define the aggregate price index $P_{t}$ as

$$
P_{t}=P_{c, t}^{\omega_{c}} P_{i, t}^{1-\omega_{c}}
$$

where $\omega_{c}$ is the steady-state output share of the consumption sector. This aggregate price index $P_{t}$ is used to calculate economy-wide inflation, $\Pi_{t} \equiv P_{t} / P_{t-1}$.

\subsection{Shock Process}

For simplicity, we focus on the technology uncertainty shock and assume that the only source of uncertainty shocks is unexpected changes in the volatility of the technology shock. We model these changes in volatility as a stochastic volatility approach, recently used by Basu and Bundick (2012), Andreasen, Fernández-Villaverde, and Rubio-Ramírez (2013), and Fernández-Villaverde, Guerrón-Quintana, Kuester, and Rubio-Ramírez (2015). Hence, we assume the law of motion for the aggregate technology as follows:

$$
\begin{gathered}
A_{t}=\left(1-\rho_{a}\right) A+\rho_{a} A_{t-1}+\sigma_{a, t} \epsilon_{t}, \\
\sigma_{a, t}=\left(1-\rho_{\sigma}\right) \sigma_{a}+\rho_{\sigma} \sigma_{a, t-1}+\sigma_{v} v_{t},
\end{gathered}
$$

where $\left|\rho_{a}\right|<1,\left|\rho_{\sigma}\right|<1, A$ is the steady-state level of technology, which is assumed to be unity, and $\sigma$ is the steady-state volatility of technology. Here, $\epsilon_{t}$ is a standard first-moment shock that affects the 
level of the stochastic process for technology. $v_{t}$ is a second-moment or "uncertainty" shock since it represents innovations to the volatility of technology. An increase in the volatility of the shock process increases the uncertainty about the future time path of the stochastic process. $\epsilon_{t}$ and $v_{t}$ are independent, standard normal random variables.

\section{Impact of Uncertainty Shocks}

In this section, we demonstrate, both analytically and numerically, that the two-sector sticky price model featuring imperfect factor mobility can lead to a rise in the relative price of investment, causing co-movement between consumption and investment in response to the uncertainty shock. Furthermore, we present empirical evidence supporting the underlying mechanism through which higher uncertainty raises the relative price of investment goods in our model.

As argued in the Introduction, due to the nature of long-lived goods, it is empirically plausible that investment goods are flexibly priced (e.g., Bouakez et al., 2009; Bils et al., 2013; Kim and Katayama, 2013). Thus, in what follows we focus on models with a sticky-price consumption sector and a flexible-price investment sector.

\subsection{Analytical Discussion}

Before simulating the model, we present an analytical argument that provides insight into how uncertainty shocks affect the relative price of investment goods in our model. Due to monopolistic competition with the constant elasticity of demand, firms with flexible prices simply charge their prices to maintain the desired constant markup over their nominal marginal costs; $P_{j, t}=\mu_{j} M C_{j, t}$, where $\mu_{j}$ is the desired price markup, and $M C_{j, t}$ is nominal marginal cost in sector $j$. By contrast, firms with sticky prices experience a temporary deviation of their price markup from the desired level. In other words, the price markup of firms with sticky prices will vary over time in response to uncertainty shocks, so that $P_{j, t}=\mu_{j, t} M C_{j, t}$, where $\mu_{j, t}$ is a time-varying price markup. The nominal marginal cost associated with the production function, (10), is given by

$$
M C_{j, t}=A_{t}^{-1}\left(\frac{1}{1-\alpha}\right)^{1-\alpha}\left(\frac{1}{\alpha}\right)^{\alpha}\left(W_{j, t}\right)^{1-\alpha}\left(R_{j, t}^{k}\right)^{\alpha} .
$$


The relative price of investment goods, $p_{t}=P_{i, t} / P_{c, t}$, is then given by

$$
p_{t}=\frac{\mu_{i, t}}{\mu_{c, t}} \frac{M C_{i, t}}{M C_{c, t}}=\frac{\mu_{i}}{\mu_{c, t}}\left(\frac{W_{i, t}}{W_{c, t}}\right)^{1-\alpha}\left(\frac{R_{i, t}^{k}}{R_{c, t}^{k}}\right)^{\alpha} .
$$

Equation (21) clearly shows that higher uncertainty exerts two counteracting effects on the relative price of investment goods. On the one hand, an increase in uncertainty pushes the relative price of investment goods down through an increase in the price markup in the sticky-price consumption sector. Faced with heightened uncertainty, the household is willing to work longer hours for a given level of real wages. In other words, higher uncertainty induces precautionary labor supply because it increases the forward-looking marginal utility of wealth. This, in turn, reduces firms' marginal costs in each sector. Falling marginal costs with slowly adjusting prices in the consumption sector imply an increase in price markups over nominal marginal costs, resulting in a drop in the production of the consumption sector. By contrast, firms in the flexible-price investment sector maintain their markups. As a result, the relative price of investment goods drops.

On the other hand, imperfect factor mobility mitigates this downward pressure on the relative price and can even raise it. When production of sticky-price consumption goods falls because of the increase in the price markup, consumption-sector wages fall relative to investment-sector wages. If labor can flow freely across sectors, workers will move from the consumption sector toward the investment sector to exploit the higher wages in the investment sector until the wages in both sectors are equalized. However, if the workers used to work in the consumption sector cannot be reallocated to the investment sector, the intersectoral wage differential will not be eliminated. That is, imperfect labor mobility makes the investment-sector wage higher than that of the consumption sector following uncertainty shocks. A similar logic applies to the capital immobility. Capital used to produce consumption goods cannot be reallocated to the investment sector, so that the rental rates in the investment sector remain higher relative to those of the consumption sector. As (21) shows, the rise in $W_{i, t} / W_{c, t}$ and $R_{i, t}^{k} / R_{c, t}^{k}$, in turn, works to increase the relative price of investment goods.

In summary, the factor immobility makes it more expensive to produce investment goods than consumption goods when production of the sticky-price consumption sector contracts in response to uncertainty shock. If $M C_{i, t} / M C_{c, t}$ rises sufficiently to dominate the increase in consumption-sector markup, then the relative price of investment goods can increase in response to the uncertainty 
shock. An increase in the relative price of investment goods triggers intertemporal substitution toward cheaper investment goods, resulting in a drop in production of investment sector.

\subsection{Simulations}

We now simulate the model to verify the analytical argument. We solve the model by using the third-order perturbation method with pruning, implemented in Dynare. As discussed in FernándezVillaverde, Guerrón-Quintana, Kuester, and Rubio-Ramírez (2015), the third-order approximation is necessary because changes in uncertainty start to play an independent role in the policy function without any interactions with other terms from the third order. As in Basu and Bundick (2012) and Fernández-Villaverde, Guerrón-Quintana, Kuester, and Rubio-Ramírez (2015), we present impulse responses as percentage deviations from the ergodic mean of each model variable.

To set parameter values, we essentially follow the values in Basu and Bundick (2012). Several parameters are unique in our model. We set the elasticity of intratemporal substitution in labor supply, $\theta$ to 0.3030 , the Frisch elasticity of labor supply $\eta$ to be 1.25 and the investment adjustment cost parameter $\kappa$ to be 1.43. These values are based on the estimates in the two-sector model of Katayama and Kim (2015). The parameter values used in the simulations are summarized in Table 1. Under these parameter values, the steady-state share of the flexible-price investment sector is 31 percent.

Figure 5 plots the responses of endogenous variables to the uncertainty shock. Uncertainty shock generates economic fluctuations that are consistent with our empirical findings: an increase in the relative price of investment goods and a simultaneous drop in consumption, investment, aggregate hours worked, and GDP.

As Figure 5 shows, the production of consumption goods with sticky prices falls in response to the uncertainty shock because the price markups on these goods temporarily rise above their desired level. As discussed, the increase in the price markup stems from the fact that higher uncertainty induces the precautionary labor supply effect, captured by the rise in the marginal utility of wealth, $\lambda_{t}$. In contrast, the price markups on investment goods with flexible prices do not deviate from their desired levels.

If factors of production cannot freely flow across sectors, the contraction in consumption sector, 
Table 1: Baseline Parameter Values

\begin{tabular}{cll}
\hline$\alpha$ & Capital share parameter & 0.33 \\
$\beta$ & Discount factor & 0.9987 \\
$\delta$ & Depreciation rate & 0.025 \\
$\gamma$ & Intertemporal elasticity of substitution & 0.5 \\
$\theta$ & Degree of intersectoral labor substitutability & 0.3030 \\
$\eta$ & Frisch elasticity of labor supply & 1.25 \\
$\kappa$ & Investment adjustment cost & 1.43 \\
$\phi_{p_{c}}$ & Consumption sector price adjustment cost & 160 \\
$\phi_{p_{i}}$ & Investment sector price adjustment cost & 0 \\
$\rho_{R}$ & Interest rate smoothing in the Taylor rule & 0.5 \\
$\rho_{\pi}$ & Reaction coefficient on inflation in the Taylor rule & 1.5 \\
$\rho_{y}$ & Reaction coefficient on output growth in the Taylor rule & 0.5 \\
$\Pi$ & Steady-state inflation rate & 1.0062 \\
$\varepsilon$ & Elasticity of substitution for intermediate goods & 6 \\
$\rho_{a}$ & First-moment technology shock persistence & 0.99 \\
$\rho_{\sigma}$ & Second-moment technology shock persistence & 0.83 \\
$\sigma$ & Steady-state volatility of technology & 0.01 \\
$\sigma_{v}$ & Volatility of second-moment technology shock & 0.0037 \\
\hline
\end{tabular}

in turn, makes factor prices in that sector remain lower than those of investment sector. Figure 5 shows that investment-sector wages and rental rates increase substantially relative to those of consumption sector. Given our parameter configurations, the increase in these intersectoral factor prices differential is strong enough to dominate the increase in the price markup in the stickyprice consumption sector, resulting in an increase in the relative price of investment goods. The temporary increase in the relative price of investment goods causes a shift of expenditure away from that sector and thereby reduces production of investment goods. In this case, uncertainty shocks act like negative supply shocks to the flexible-price investment sector.

Whether the model with imperfect factor mobility can replicate our empirical findings documented in Section 2 depends on parameter values, especially $\theta$, which controls the degree of labor immobility. Figure 6 shows the responses to the uncertainty shock with different values of $\theta$. As can be observed clearly, we need strong labor immobility (roughly speaking $\theta<1$ ) to generate a positive response of the relative price of investment goods as well as the co-movement among output, consumption, and investment.

Thus far, we focus on the effects of unanticipated changes in the volatility of total factor productivity (i.e., technology uncertainty shocks). Basu and Bundick (2012) and Leduc and Liu 

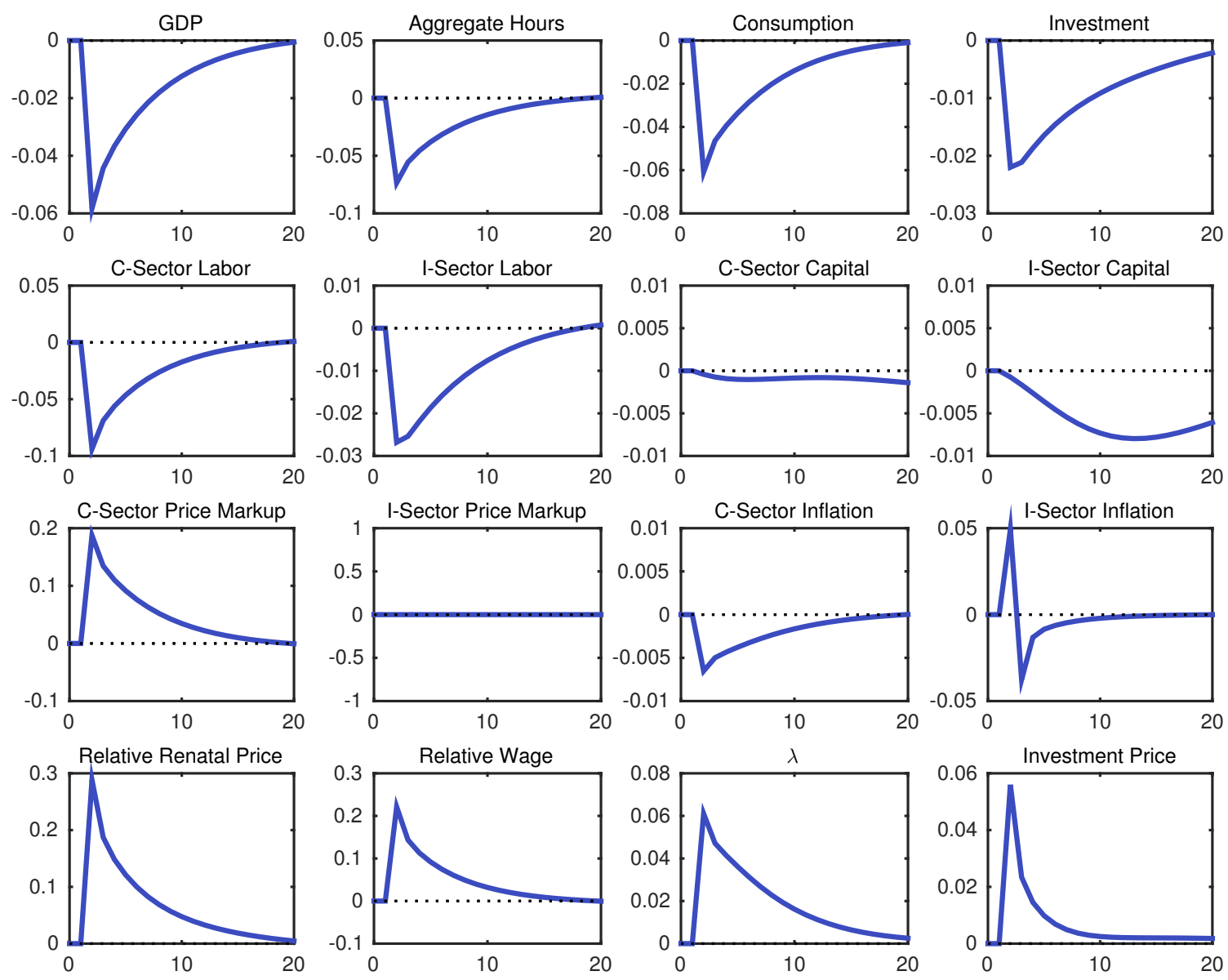

Figure 5: Responses to Technology Uncertainty Shock with Imperfect Factor Mobility

Note: The lines above represent percentage deviations from the ergodic means with the flexible-price investment sector under imperfect factor mobility. Relative rental price and wage are defined as those in the investment sector relative to the consumption sector.

(2016) consider demand uncertainty shocks. To the extent that precautionary savings and labor supply triggered by higher uncertainty affect the economy, the same logic applies to demand uncertainty shocks, and the two-sector model with imperfect factor mobility delivers qualitatively similar dynamics. Thus, regardless of the origin of aggregate uncertainty, imperfect factor mobility helps explain our empirical findings.

\subsection{Validity Check}

One sharp prediction from the model with imperfect factor mobility is that factor prices of the investment sector relative to those of the consumption sector rise in response to the uncertainty shocks. In this section, we present some supporting evidence for this prediction. Figure 7 shows 

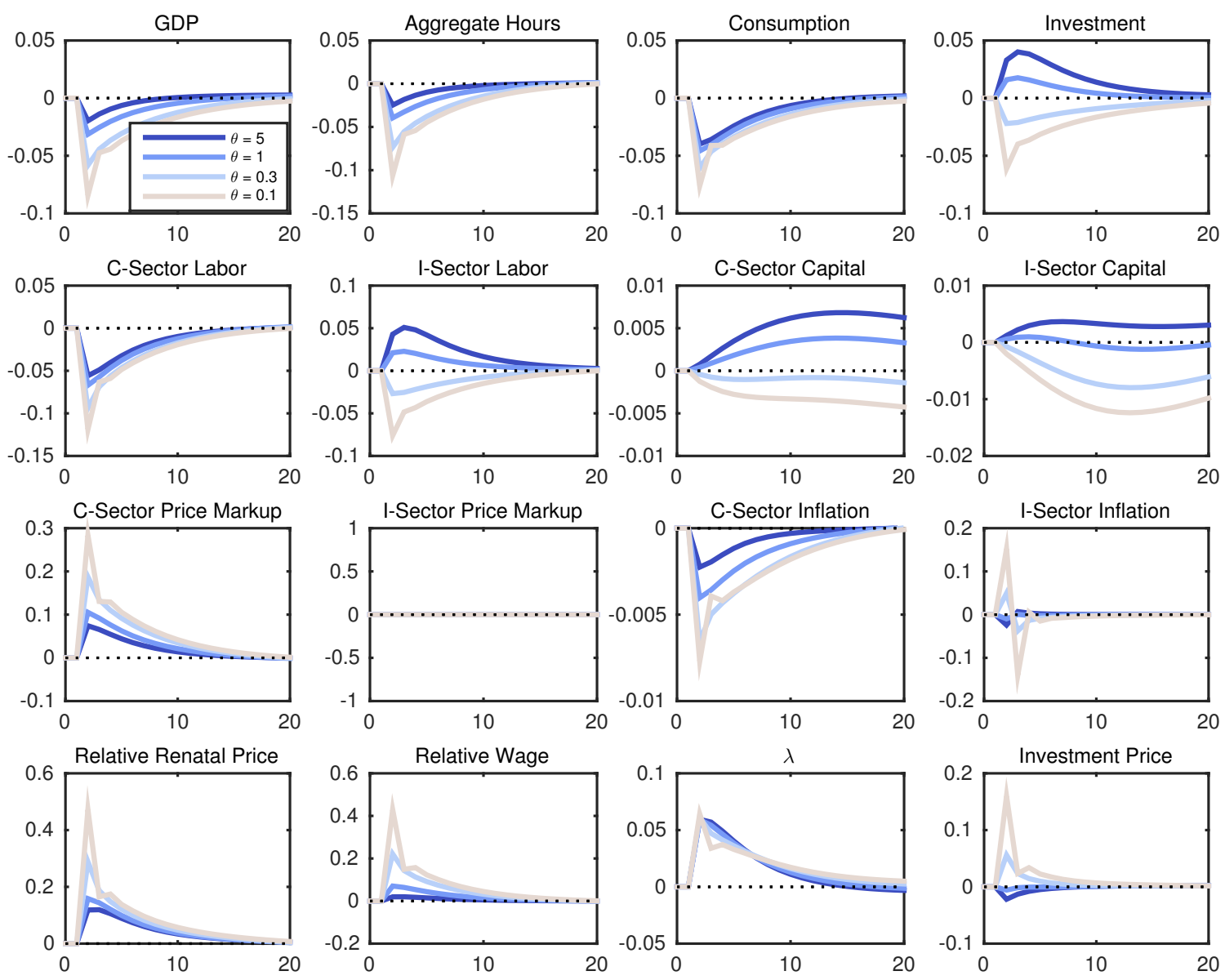

Figure 6: Responses to Technology Uncertainty Shock with Different Values of $\theta$

Note: The lines above represent percentage deviations from the ergodic means with the different values of $\theta$. As colors become lighter (from dark blue to gray), the value of $\theta$ decreases $(5,1,0.3$, and 0.1 , respectively). Relative rental price and wage are defined as those in the investment sector relative to the consumption sector.

estimated responses of the sectoral relative wage, $W_{i, t} / W_{c, t}$. These are obtained by replacing the aggregate real wage by the relative sectoral wages in the VAR specification considered in Section $2 .{ }^{11}$

Consistent with the model's prediction, the investment-sector wage relative to consumption sector rises in response to the uncertainty shock. In particular, it becomes significant two quarters after the shock. Hence, the limited intersectoral factor mobility seems to be a plausible explanation for why the relative price of investment goods increases in response to the uncertainty shocks.

\footnotetext{
${ }^{11}$ Sectoral wages are constructed using the Current Employment Statistics of the BLS, available at http://www.bls.gov/ces/cesbtabs.htm. We retrieve Tables B-6, B-7, and B-8 to obtain data on employees, average weekly hours, and average hourly earnings for construction, durable, nondurable, and services. We assume that the consumption sector consists of nondurable manufacturing and services and that the investment sector is composed of construction and durable manufacturing. We aggregate sectors by calculating total wage bills. The total wage bill is divided by the total man-hours in each sector to obtain the implicit sectoral nominal wages. Nominal wages are deflated by the consumption good price, as consistent with the two-sector setup.
} 


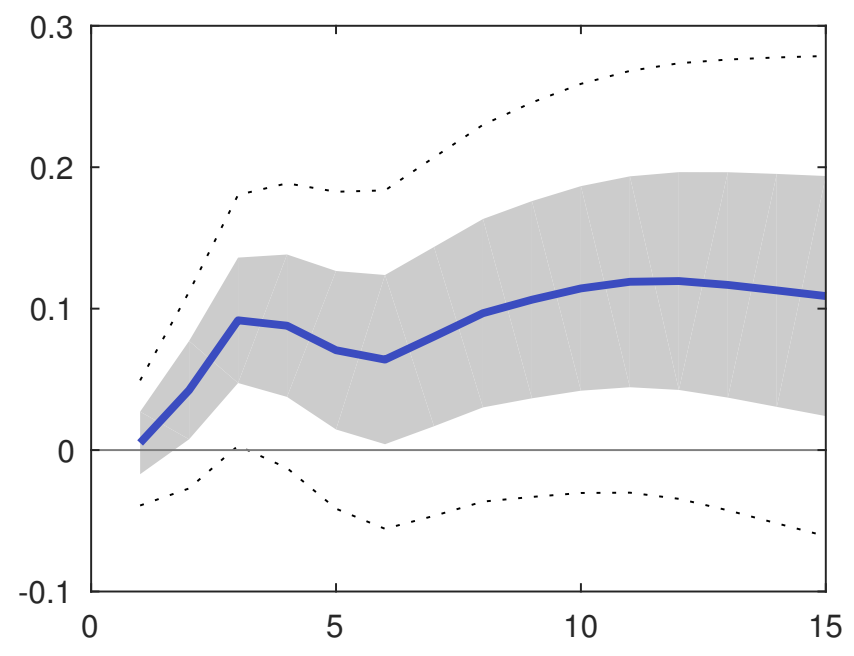

Figure 7: Estimated Responses of Relative Wage

Note: The responses of relative wage are estimated by replacing the aggregate real wage in the specification considered in Section 2 by the investment-sector wage relative to consumption sector. The horizontal axis measures quarters. The vertical axis represents percentage deviations from the unshocked path. The shaded areas and dashed lines represent one- and two-standard-error confidence bands, respectively. They are based on 1,000 bootstrap repetitions.

\section{Perfect Factor Mobility}

In this section, we examine how uncertainty shocks affect the economy as we relax the assumption of inflexible intersectoral factor mobility and instead allow factors of production to move freely across sectors. We show that the ability of two-sector sticky price models to generate our empirical findings in response to uncertainty shocks is significantly deteriorated in the economy with perfect factor mobility. In particular, higher uncertainty decreases the relative price of investment goods and generates a boom in the standard two-sector sticky price model with perfect factor mobility. This implies that the degree of intersectoral factor mobility is central to determining how uncertainty shocks are propagated to the economy.

To introduce perfect factor mobility, we assume that labor is perfect substitutes (i.e., $\theta \rightarrow \infty$ ) and capital, even though installed in a sector, can be shifted to another sector in response to the uncertainty shock. Thus, the aggregate capital stock evolves over time according to

$$
K_{t+1}=I_{t}\left[1-\frac{\kappa}{2}\left(\frac{I_{t}}{I_{t-1}}-1\right)^{2}\right]+(1-\delta) K_{t}
$$

where

$$
K_{t}=K_{c, t}+K_{i, t}
$$


In contrast with the imperfect capital mobility, while aggregate capital stock, $K_{t}$, is predetermined, sectoral capital, $K_{j, t}$, is a control variable.

To preview the impact of uncertainty shock in the standard two-sector model with perfect factor mobility, it is useful to note that the relative price $p_{t}$, given in (21), is now modified to:

$$
p_{t}=\frac{\mu_{i, t}}{\mu_{c, t}} \frac{M C_{i, t}}{M C_{c, t}}=\frac{\mu_{i}}{\mu_{c, t}} .
$$

If factors can flow freely across sectors, nominal wages and rental rates will equalize across sectors, which implies that firms in each sector will have the same nominal marginal costs. Hence, in the standard two-sector model, the movements in the relative price of investment goods is only driven by the difference in sectoral price markups.

As discussed above, higher uncertainty has a differential impact on sectoral price markups because of asymmetric price rigidity across sectors. It lowers the price markups on consumption goods with sticky prices through the precautionary labor supply effect, causing the production of the consumption sector to drop. Firms in the flexible-price investment sector simply charge lower prices and thus maintain their desired markups as higher uncertainty induces the precautionary labor supply effect. Hence, an increase in uncertainty leads to a decline in the relative price of investment goods in the standard two-sector model. The lower relative price of investment goods causes intertemporal substitution toward those goods, resulting in an increase in production of the investment sector. Therefore, the standard two-sector model with flexible-price investment sector generates a negative co-movement problem between consumption and investment and counterfactually predicts the decline in the relative price of investment goods in response to uncertainty shocks.

Simulation confirms the prediction of the discussion above. The dark blue lines in Figure 8 presents responses of endogenous variables to the uncertainty shock in the standard two-sector model with flexible-price investment sector. In response to the uncertainty shock, the relative price of investment drops and the model exhibits a lack of business cycle co-movement: consumption declines, but investment rises. This co-movement problem is interesting because it resembles that of Barsky, House, and Kimball (2007). They show that the presence of flexible-price durable goods also generates negative co-movement between nondurable and durable goods in response to monetary 

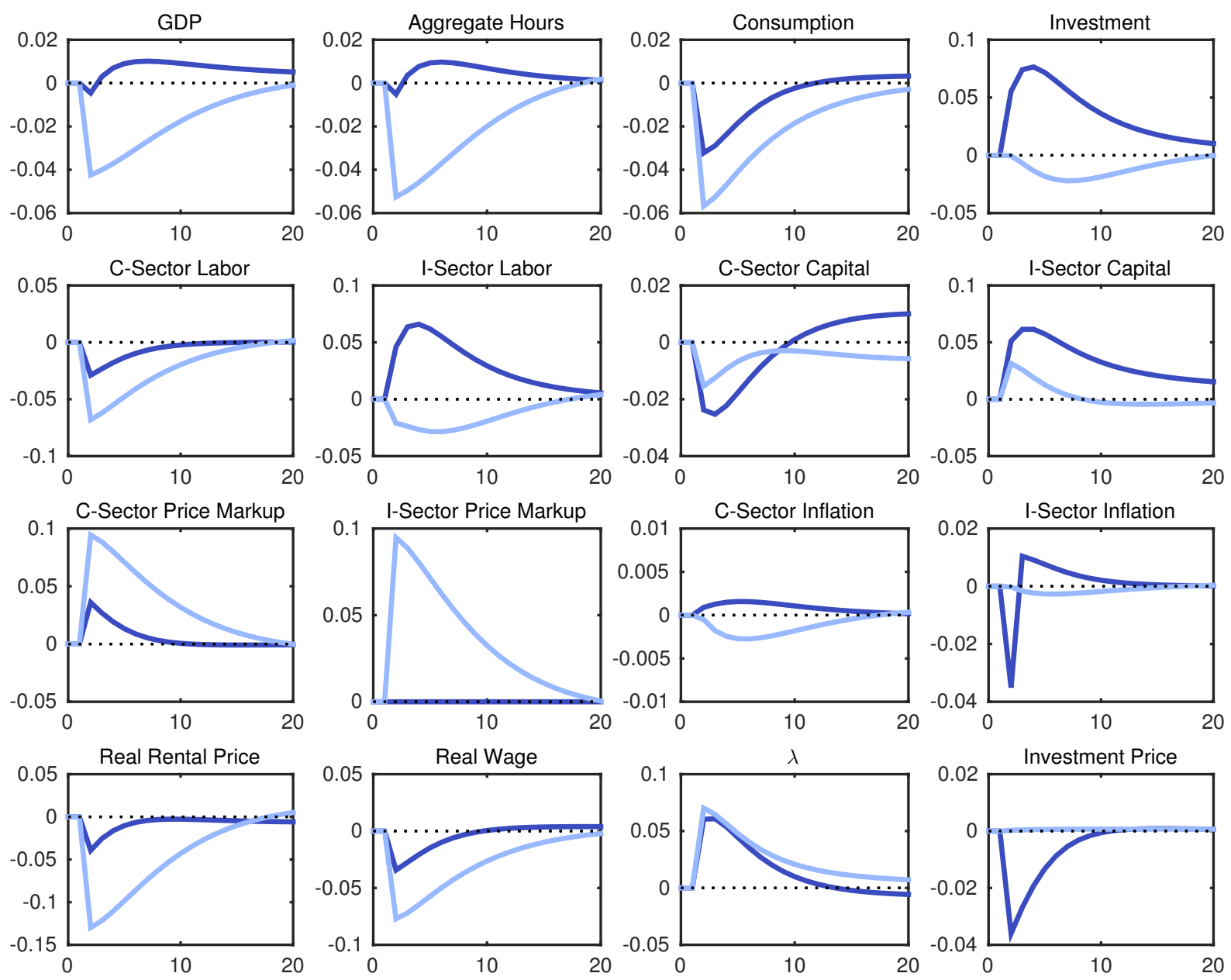

Figure 8: Responses to Technology Uncertainty Shock with Perfect Factor Mobility

Note: Dark blue lines show percentage deviations from the ergodic means with the flexible-price investment sector $\left(\phi_{p_{c}}=160, \phi_{p_{i}}=0\right)$. Light blue lines represent those with symmetric price rigidity $\left(\phi_{p_{c}}=\phi_{p_{i}}=160\right)$.

policy shocks. Hence, our result here suggests that the co-movement problem associated with flexibly priced durable goods can be more general in that it is not specific to monetary shocks, but can also arise in response to uncertainty shocks. ${ }^{12}$

What is more surprising is the behavior of aggregate hours worked and output. Heightened uncertainty produces an expansion in aggregate economic activity: aggregate hours worked and output rise! To a certain extent, the behavior of the standard two-sector sticky price model with

\footnotetext{
${ }^{12}$ As Carlstrom and Fuerst (2010) demonstrate that the introduction of sticky wages can resolve the negative comovement problem with respect to monetary shock, one might conjecture that it can be an alternative to the imperfect factor mobility in accounting for our empirical findings. In our experiments, however, we find that adding sticky wages to the standard model does not eliminate the negative co-movement problem of consumption and investment even though wage becomes extremely rigid. Furthermore, the relative price of investment goods continues to fall in response to the uncertainty shock even after sticky wages are introduced, which is at odds with our empirical findings. The results are available upon request.
} 
flexible-price investment goods is unexpected. Because there is a fall in the production of stickyprice consumption, the lion's share of output, it is natural to think that aggregate hours and output will drop in response to the uncertainty shock. However, Figure 8 clearly shows that this logic is misleading and the standard two-sector model has difficulty in generating even an adverse effect on aggregate economic activity.

The intuition behind this result is as follows. Unlike consumption goods, the pertinent feature of productive durable goods is it low depreciation rate (i.e., its longevity). As pointed out by Barsky, House, and Kimball (2007), long-lived durable goods have a high degree of intertemporal elasticity of substitution. Thus, the temporary reduction in the relative price of investment goods can induce a substantial expansion of investment sector so as to dominate the contraction of consumption sector, causing aggregate hours and output to rise.

Interestingly, the behavior of the standard two-sector sticky price model with flexible price investment sector contrasts sharply with that of a one-sector sticky price model. Basu and Bundick (2012) demonstrate that uncertainty shocks cause aggregate hours and GDP to drop in the onesector sticky price model. To show this, we simulate the standard two-sector sticky price model with identical price rigidity across sectors, which collapses into the one-sector model. In contrast with the model with asymmetric price rigidity, the light blue lines in Figure 8 show that aggregate hours and output fall together in response to the uncertainty shock in the model with symmetric price rigidity. This result essentially replicates the key result of Basu and Bundick (2012), which is obtained in a one-sector sticky price model. Hence, the presence of the flexible-price investment sector can undo the implications of the one-sector sticky price model and thus makes it extremely difficult for sticky price models to generate the adverse effect in response to uncertainty shocks.

\section{Conclusion}

In this study, we present empirical evidence that higher uncertainty not only leads to a simultaneous drop in consumption and investment, but also a rise in the relative price of investment goods. This negative relationship between the relative price and production of investment suggests that uncertainty shock acts as an adverse supply shock to the investment sector. On the contrary, many researchers stress the demand-side channel by which uncertainty shocks cause a slowdown in eco- 
nomic activity through depressing investment demand due to the "real-options" effect. Therefore, our empirical findings shed new light on understanding the nature of uncertainty shocks.

To account for our empirical findings, we consider a two-sector, representative-agent sticky price model that consists of a sticky-price consumption sector and a flexible-price investment sector. We show that the model can successfully generate a profile of the impulse responses to the uncertainty shock that is consistent with our empirical evidence. The key to the model's success is limited intersectoral factor mobility. Imperfect factor mobility makes uncertainty shocks behave like adverse supply shocks to the flexible-price investment sector, causing a rise in the relative price and a drop in the production of investment goods. Production in the sticky-price consumption sector drops in response to uncertainty shock because of the precautionary savings effect.

By contrast, the standard two-sector sticky price model featuring perfect factor mobility generates perverse behavior if investment goods have flexible prices. The model causes a negative co-movement problem between consumption and investment in response to uncertainty shocks. Interestingly, this result resembles that of Barsky, House, and Kimball (2007) who show that the presence of flexibly priced durables also causes the co-movement problem in response to monetary shock.

Even though the model with imperfect factor mobility can qualitatively deliver co-movement among the key macroeconomic variables as well as the rise in the relative price of investment goods, there are several aspects yet to be explained. In particular, while the estimated response of investment is much more pronounced than consumption, the response of investment is somewhat moderate compared with that of consumption in the model. Tackling these issues is beyond the scope of the current study and we will leave them for future research. 


\section{References}

Alexopoulos, M. And J. Cohen (2009): “Uncertain Times, uncertain measures,” Working Paper 352, University of Toronto, Department of Economics.

Andreasen, M. M., J. Fernández-Villaverde, and J. Rubio-Ramírez (2013): “The pruned state-space system for non-linear DSGE models: Theory and empirical applications," Working Paper 18983, National Bureau of Economic Research.

Bachmann, R. ANd C. Bayer (2013): “Wait-and-See' business cycles?" Journal of Monetary Economics, $60,704-719$.

Bachmann, R., S. Elstner, and E. R. Sims (2013): “Uncertainty and Economic Activity: Evidence from Business Survey Data," American Economic Journal: Macroeconomics, 5, 217-49.

Baker, S. R., N. Bloom, and S. J. Davis (2016): "Measuring Economic Policy Uncertainty*," The Quarterly Journal of Economics, 131, 1593.

Barsky, R. B., C. L. House, and M. S. Kimball (2007): “Sticky-price models and durable goods," American Economic Review, 97, 984-998.

BAsu, S. And B. Bundick (2012): “Uncertainty Shocks in a Model of Effective Demand," Working Paper 18420, National Bureau of Economic Research.

Basu, S. and M. S. Kimball (2002): “Long-run labor supply and the elasticity of intertemporal substitution for consumption," Working paper.

Beaudry, P. And F. Portier (2011): “A gains from trade perspective on macroeconomic fluctuations," Working Paper 17291, National Bureau of Economic Research.

Bils, M., P. J. Klenow, And B. A. Malin (2013): “Testing for Keynesian Labor Demand,” NBER Macroeconomics Annual, 27, 311 - 349.

Bloom, N. (2009): “The Impact of Uncertainty Shocks,” Econometrica, 77, 623-685.

(2014): “Fluctuations in uncertainty," Journal of Economic Perspectives, 28, 153-76. 
Bloom, N., M. Floetotto, N. Jaimovich, I. Saporta-Eksten, and S. J. Terry (2012): “Really Uncertain Business Cycles," Working Paper 18245, National Bureau of Economic Research.

Born, B., S. Breuer, And S. Elstner (2014): “Uncertainty and the Great Recession,” Working Papers 04/2014, German Council of Economic Experts / Sachverständigenrat zur Begutachtung der gesamtwirtschaftlichen Entwicklung.

Bouakez, H., E. Cardia, and F. J. Ruge-Murcia (2009): “The Transmission of Monetary Policy in a Multisector Economy," International Economic Review, 50, 1243-1266.

Caggiano, G., E. Castelnuovo, and N. Groshenny (2014): “Uncertainty shocks and unemployment dynamics in U.S. recessions," Journal of Monetary Economics, 67, 78-92.

Carlstrom, C. T. and T. S. Fuerst (2010): “Nominal Rigidities, Residential Investment, and Adjustment Costs," Macroeconomic Dynamics, 14, 136-148.

Carriero, A., H. Mumtaz, K. Theodoridis, and A. Theophilopoulou (2015): “The Impact of Uncertainty Shocks under Measurement Error: A Proxy SVAR Approach," Journal of Money, Credit and Banking, 47, 1223-1238.

Christiano, L. J., M. Eichenbaum, and C. L. Evans (2005): “Nominal Rigidities and the Dynamic Effects of a Shock to Monetary Policy," Journal of Political Economy, 113, 1-45.

Davis, S. J. And J. Haltiwanger (2001): “Sectoral job creation and destruction responses to oil price changes," Journal of monetary economics, 48, 465-512.

DiCecio, R. (2009): “Sticky Wages and Sectoral Labor Comovement," Journal of Economic Dynamics and Control, 33, 538-553.

Fernández-Villaverde, J., P. Guerrón-Quintana, K. Kuester, and J. Rubio-Ramírez (2015): “Fiscal Volatility Shocks and Economic Activity," American Economic Review, 105, 3352-84.

Gilchrist, S., J. W. Sim, And E. ZaKrajŠEKeK (2014): “Uncertainty, Financial Frictions, and Investment Dynamics," Working Paper 20038, National Bureau of Economic Research.

Hamilton, J. D. (1983): “Oil and the Macroeconomy since World War II," Journal of Political Economy, 91, 228-248. 
- (1996): "This is what happened to the oil price-macroeconomy relationship;" Journal of Monetary Economics, 38, 215-220.

(2003): “What is an oil shock?" Journal of Econometrics, 113, 363-398.

Horvath, M. (2000): “Sectoral shocks and aggregate fluctuations," Journal of Monetary Economics, 45, 69-106.

Jurado, K., S. C. Ludvigson, and S. Ng (2015): “Measuring uncertainty," American Economic Review, $105,1177-1216$.

Justiniano, A., G. Primiceri, And A. Tambalotti (2011): “Investment Shocks and the Relative Price of Investment," Review of Economic Dynamics, 14, 101-121.

Katayama, M. And K. H. Kim (2015): “Inter-sectoral Labor Immobility, Sectoral Comovement, and News Shocks," Working Paper E-15-011, Kyoto University.

Kim, K. H. and M. Katayama (2013): “Non-separability and sectoral comovement in a sticky price model," Journal of Economic Dynamics and Control, 37, 1715 - 1735.

Krueger, A. B. And L. H. Summers (1988): “Efficiency Wages and the Inter-Industry Wage Structure," Econometrica, 56, 259-293.

LEDUC, S. AND Z. LiU (2016): “Uncertainty shocks are aggregate demand shocks," Journal of Monetary Economics, 82, 20-35.

Ludvigson, S. C., S. MA, ANd S. Ng (2016): “Uncertainty and Business Cycles: Exogenous Impulse or Endogenous Response?" Working Paper.

Neumuller, S. (2015): “Inter-Industry Wage Differentials Revisited: Wage Volatility and the Option Value of Mobility," Journal of Monetary Economics, 76, 38-54.

Ramey, V. A. ANd M. D. Shapiro (2001): “Displaced capital: A study of aerospace plant closings," Journal of Political Economy, 109, 958-992.

Rotemberg, J. J. (1982): “Sticky Prices in the United States,” Journal of Political Economy, 90, 1187-1211. 
Shimer, R. (2009): “Convergence in macroeconomics: The labor wedge," American Economic Journal: Macroeconomics, 280-297.

Wu, J. C. And F. D. XIA (2016): “Measuring the Macroeconomic Impact of Monetary Policy at the Zero Lower Bound," Journal of Money, Credit and Banking, 48, 253-291. 